\title{
PREDICTING THE DURATION OF CONCRETE OPERATIONS VIA ARTIFICIAL NEURAL NETWORK AND BY FOCUSING ON SUPPLY CHAIN PARAMETERS
}

\author{
MOJTABA MAGHREBI ${ }^{1}$, CLAUDE SAMMUT ${ }^{2}$ and TRAVIS S. WALLER ${ }^{1}$
}

\begin{abstract}
Being able to precisely predict the duration of concrete operations can help construction managers to organize sites and machineries more efficiently, especially when there is limited space for equipment on site. Currently there is no theoretical method for estimating the duration of the concrete pouring process. Normally, the maximum capacity of pumping facilities on construction sites is not used, and concrete pumps are idle for a considerable time as a result of the arrival of concrete trucks being delayed. In the light of this issue, this paper considers the supply chain parameters of Ready Mixed Concrete (RMC) as a means of solving this problem. Artificial Neural Network (ANN) is hired for modelling/predicting the productivity of a concrete operation. The proposed model is tested with a real database of an RMC in the Sydney metropolitan area that has 17 depots and around 200 trucks. Results show that there is an improvement in the achieved results when these are compared to the results of relevant studies that only considered the construction parameters for predicting the productivity of concrete operations.
\end{abstract}

Keywords: RMC, productivity, supply chain

\section{Introduction}

In construction, concrete plays a key role as the world`s most used construction material (Kosmatka et al., 2002). It is also expected that the demand for concrete will increase in the future (Imbabi et al., 2012, Council, 2009, Humphreys and Mahasenan, 2002, Damtoft et al., 2008, Rosenthal, 2007, Mahasenan et al., 2003, Worrell et al., 2001, Mehta, 2009) This issue is studied in detail in the report published by International Cement Review (ICR) (Armstrong 2013). They reviewed the cement market in 165 countries over 22 years. This comprehensive study emphasizes that regardless to the geographical location the demand for concrete increase globally. Therefore, it is a necessity that the ready mixed concrete (RMC) industry is enhanced to cope with higher demands.

Most of the publications in the RMC domain have been devoted to implementing heuristic methods which Genetic Algorithm (GA) has been highlighted more than other heuristic methods. Garcia et al. (2002) modelled the RMC for a single depot and solved it via optimization and GA. However, their approach is not practical because some realistic constraints were relaxed and considered only small instances. (Feng et al., 2004) also modelled a single depot RMC and assumed some parameters such as loading/unloading times as fixed

\footnotetext{
${ }^{1}$ The University of New South Wales (UNSW), School of Civil and Environmental Engineering, Sydney, Australia, e-mail: maghrebi@unsw.edu.au

2 The University of New South Wales (UNSW), School of Computer Science Engineering Sydney, Australia
} 
parameters. The instances that have been considered by them are much smaller than the instances that are used in this paper. Naso et al. (2007) modelled a more realistic RMC problem by considering multi-depots and penalizing the waiting times (loading/unloading) in the objective function. They also introduced a GA algorithm which is very similar to the methods that were presented earlier by Garcia et al. (2002) and Feng et al. (2004). However, the instances that Naso and colleagues have tested are larger than in the previous research. Lu (2002 and 2003) developed a software package called HCKCONSIM to deal with real RMC problems. This mainly concerned the discrete event simulation (DES) tool but in its recent versions was coupled with heuristic solvers such as GA (Cao et al., 2004, Lu and Lam, 2005, Ming and HoiChing, 2009), Particle Swarm Optimization (PSO) (Lu et al., 2006, Wu et al., 2005) and real GPS data of trucks (Lu et al., 2007) in order to make a more powerful tool. Feng and Wu (2006) and Cheng and Yan (2009) had a similar approach by integrating DES with a fast messy GA algorithm. Silva et al. (2005) compared GA with Ant Colony Optimization (ACO) and suggested a GA-ACO method for solving RMC problems. Pan et al. (2010) proposed an improved Discrete PSO (DPSO) for solving RMC dispatching problems and recently Srichandum and Rujirayanyong (2010) compared Bee Colony Optimization (BCO) and Tabu Search (TS) with GA in this context. Despite developments in this area, the solution structure among most introduced methods is pretty much same, especially in the GA based method where the chromosome structure consists of two merged parts: the first part defines the sources of deliveries; the second part expresses the priorities of customers. The solution structure in these techniques is quite simple and easy to understand. However, a cumbersome computing process must be completed in each iteration to check the constraints or after achieving a premature solution.

In the literature, rather than GA some other approaches also have been studied that will be discussed briefly in the text that follows. Yan et al. (2008) introduced a numerical method for solving the RMC optimization problem by cutting the solution space and incorporating the branch and bound technique and the linear programming method. Lin et al. (2010) modelled the RMC as a job shop problem. Yan et al. (2012) used decomposition and relaxation techniques coupled with a mathematical solver to solve the problem, and Payr and Schmid (2009) applied Variable Neighborhood Search (VNS) to deal with RMC optimization problems. Asbach et al. (2009) made the mathematical modelling much simpler by dividing the depots and customers into sub-depots and sub-customers. They also used large scale instances for testing their introduced large neighborhood search and decomposition methods.

It has been found that of the related works in the literature about RMC only Graham et al (Graham et al., 2006) consider this issue in detail. The concern of these authors is in predicting the duration of concrete operations accurately. In this regard they used Artificial Neural Network (ANN) and tested it via a real database. They assumed that the duration of an operation is related to the construction situation. Therefore, they collected data from four actual construction projects which consisted of the following attributes: month of operation, type of operation, truck volume, total operation volume, average interarrival time, number of loads in operation, number of accepted loads and number of rejected loads. It appears that they assumed that there is no limitation for RMCs and the required trucks usually arrive at construction sites without any delay, which in reality is not completely true. Graham et al (Graham et al., 2006) indirectly assumed that the duration is related to the type of construction operation (wall, column, slab), truck volume, interarrival time and ... etc.

However, in the authors' opinion the RMC conditions have a significant impact on the duration of the operation. In other words, environmental variables must also be taken into 
account. For example, the duration of a concrete pouring task in a project which is located in a city with dense traffic would be different from one in a small city with far less traffic. Furthermore, the travel time between a depot and a project in the early morning varies from the travel time at midday. Travel times from/to some locations during the day vary considerably although they are less critical on non-working days. The importance of a quality prediction emerges when a concrete pump and workers are around $12 \%$ idle on the site, making for an additional $14 \%$ cost (Graham et al., 2006). Consequently, it is necessary to have a more accurate prediction of the duration of the operation.

The second contribution of this paper is the size and amount of data that is used in this paper which is much greater than the datasets that have been used in similar research in literature. The richness of data helps the authors to conclude confidently.

\section{Methodology}

Typically, fresh concrete is hauled by trucks from batch plants to the construction sites and then placed in frames to construct concrete elements. A project might need several deliveries; therefore the required trucks must arrive at the site consecutively. However, there is no general model in the literature that can predict the duration of a concrete operation precisely.

It is recommended to take into consideration the both internal and external parameters. It is not intended to check the available data with several algorithms in order to find which algorithm outperforms others. Although this would be valuable and the researchers might consider doing this in the future, in this paper the authors want to place more emphasis on how machine learning techniques - and specifically ANN - can be hired in construction management more effectively. In this paper, then, the problem is considered in general terms and from the perspective of both clients and RMCs. In this regard, first the proposed attributes are justified. Second, the ANN model is introduced. Third, the features of the available database are examined. Finally, the achieved results are discussed and compared with relevant research. It is worthy to note that authors do not intend to estimate the size of crew or machinery for concrete pouring which has been discussed in literature extensively (Thomas and Sakarcan, 1994, Thomas et al., 1984, Thomas and Daily, 1983, Thomas, 1991, Sonmez and Rowings, 1998, Crawford and Vogl, 2006, Borcherding and Alarcon, 1991, Zahraee et al., 2013, Dunlop and Smith, 2004). Beyond the construction sites there are important variables that have not been carefully taken into account for predicting the productivity of concrete pouring. These variables will be associated into the proposed ANN based model to predict the duration of concrete pouring effectively.

\section{Data structure}

As mentioned above, this paper aims to consider both the execution and supply chain parameters related to concrete operation in the modelling process. It is recommended that a database contains the following parameters which cover the affective parameters of the duration of the operation.

- Weekday: The travel time for some areas is considerably different on working days and nonworking days. A digit between 1 and 7 is assigned for each day of week. For example, Monday $=1$ and Friday $=5$.

- Starting Time of First Delivery: The duration of an operation would vary depending, for instance, on whether it commences during a rush hour or at midnight. In this regard, the time of arrival of the first truck to the site is extracted from the database. The ANN accepts 
nominal attribute so the time must be converted to the real number, for example 13.75 instead of $1: 45 \mathrm{pm}$.

- Total Amount of Ordered Concrete: For each project the total amount of delivered concrete is extracted from the available data. This is expressed as a real number with one decimal.

- Location of Project: Predicting travel times cannot rely too much on the distance alone because the speeds of trucks on some routes fluctuate in the course of a day. Therefore, an expected arrival time based only on distance cannot be precise. Moreover, some parts of metropolitan areas have different traffic patterns during day. The authors believe that geolocation data that includes longitude and latitude can possibly convey this information. Each location (depots or projects) has unique longitude and latitude that are extracted from available database with arithmetic precision to six digits. Thus, it is expected that these provide enough information for the algorithms to determine the reasonable correlation between geo-locations and other attributes. Possibly both attributes of the "Starting Time of First Delivery" and "Location of Project" can in conjunction deliver the traffic pattern for each location which would have significant impact on travel times.

- Total Number of Received Orders by RMC: This attribute becomes important when an RMC has accepted numerous deliveries in a day. Possibly for some hours the available resources of the RMC are not sufficient and demand is greater than supply. In such situations RMCs stretch the interarrival times to balance demand and supply. This makes supplying some deliveries possible although perhaps later than expected. Thus, this attribute can reflect how busy the RMC is.

- Total Number of Assigned Deliveries to the Source Depot: The former attribute shows the density of orders through the day; however, this attribute can reflect the same issue but particularly for the allocated depot which is chosen to supply concrete to the project. This attribute is selected when, for instance, an RMC has received many orders but demands are not distributed among the supply area smoothly. In the other words, a depot can have a large number of orders in some areas but very few orders in other areas; in such cases it is expected that this attribute will assist ANN to realize this issue. For large projects with more than 30 deliveries, normally concrete is supplied from more than one depot. However, based on the supplied records we still can recognize a depot as the main depot in database.

- Productivity: This is calculated by dividing the total amount per duration; its unit is $\mathrm{m}^{3} / \mathrm{hr}$.

As it was mentioned the proposed method will not associate all the construction site parameters directly in the model. For example: the proposed model does not associate the pouring system (crane or pump) or type of operation (wall, column or base) in the calculation.

\section{Artificial neural network}

The concept underlying Artificial Neural Network (ANN) was inspired by the biological nervous system (McCulloch and Pitts, 1943). A considerable amount of literature has been published on ANN and its applications; however, in this paper we will discuss only some ANN applications in construction management.

Moselhi and colleagues are among the first scholars to research ANN as a promising management tool in construction (Moselhi et al., 1991). Following on from their work, Savin et al. (1996) used ANN for resource leveling. The implementation of ANN for pavement management was conducted by Brega et al. (1998). A large and growing body of literature has investigated the prediction of earthmoving process by ANN such as (Shi, 1999, Chao and 
Skibniewski, 1994, Kartam, 1996, Flood and Christophilos, 1996) and similarly for concrete framework production (Portas and AbouRizk, 1997). ANN has also been implemented in predicting complex issues in construction such as labour productivity (AbouRizk and Wales, 1997, Lu et al., 2000). Cost estimations on reconstruction projects via ANN was discussed by Attalla and Hegazy (2003). Enhancing ANN with fuzzy logic and its application in estimating contractors` markup has been studied by Liu and Ling (2003). Chehayeb et al. (2007) studied the classification of construction court cases in Canada by ANN. Ko and Cheng (2007) fused genetic algorithms, fuzzy logic and ANN to predict the success of construction projects dynamically. Chen and Hsu (2007) introduced a method for solving potential lawsuit problems as a result of changing orders via merging ANN and case-based reasoning (CBR). Shi and Li (2008) adopted particle swarm optimization (PSO) in ANN for assessing and predicting the quality of construction projects in China. Predicting the performance of international construction projects was studied by Kim et al. (2009). Cheng et al. (2009) proposed an ANNbased model for achieving strategic control over project cash flows. Jin and Zhang (2011) suggested an ANN-based model to model the risk allocation in public private partnership (PPP) projects. The application of ANN in knowledge management in construction firms was studied by Kale and Karaman (2011). Kim (2013) offered technique for accurately estimating the highway project in South Korea by analytic hierarchy process (AHP), CBR and ANN.

It can be deduced from the applications of ANN in construction that this algorithm is a capable tool for predicting complex processes and tasks. Other scholars have claimed that ANN is an adaptive learning algorithm (Darrat and Zhong, 2000, Szu et al., 1992, Fast and Palme, 2010, Qin et al., 2013, Zor et al., 2012), which means it is capable of finding a relationship between inputs and outputs.

In this paper, MATLAB neural network fitting tool is used for training, validation and testing the proposed problem. MATLAB uses the Levenberg-Marquardt (LM) algorithm (Levenberg, 1944, Marquardt, 1963) which is a backpropagation ANN. LM is originally a numerical method for finding the minimum of a function, especially the least square curve fitting problems. All the computational related processes have been developed in MATLAB with a core duo $3.00 \mathrm{GHz}$ processor, 8.00 GB RAM on Windows 7 Enterprise.

As mentioned above, the aim is not to find the best algorithm for predicting the productivity among the machine learning algorithms. Nevertheless, according to the achievements of Graham et al (Graham et al., 2006), LM is a proper choice for modelling and predicting the productivity of the concrete pouring process. This algorithm is used in this paper for the same objective but with a totally different data structure than has been proposed in the prior section. The architecture of ANN is illustrated in Figure 1. This kind of feed-forward ANN algorithm has connections between side layers. In this paper the number of hidden layers is selected from 2 to 10. A slight improvement in results was observed when the number of hidden layers was increased; however, the differences are not significant. Therefore, in this paper only the results of ANN model with 10 hidden layers are reported. MSE and R2 (coefficient of determination) are the most important parameters which are used for measuring the quality of predictions.

$$
\operatorname{MSE}=\frac{1}{n} \sum_{i=1}^{n}\left(Y_{i}-T_{i}\right)^{2}
$$

When:

$n=$ the number of instances

$T_{i}=$ Target (actual) value of instances $i$

$Y_{i}=$ Predicted value for instances $i$ 
The coefficient of determination (R2) is another assessing parameter that measures the correlation between targets and predicts among the database. Its calculation is mentioned in (eq. 2).

$$
R^{2}=1-\frac{\sum_{i}\left(T_{i}-Y_{i}\right)^{2}}{\sum_{i}\left(T_{i}-\bar{T}\right)^{2}}
$$

When:

$$
\overline{\mathrm{T}}=\frac{1}{n} \sum_{i=1}^{n} T_{i}
$$

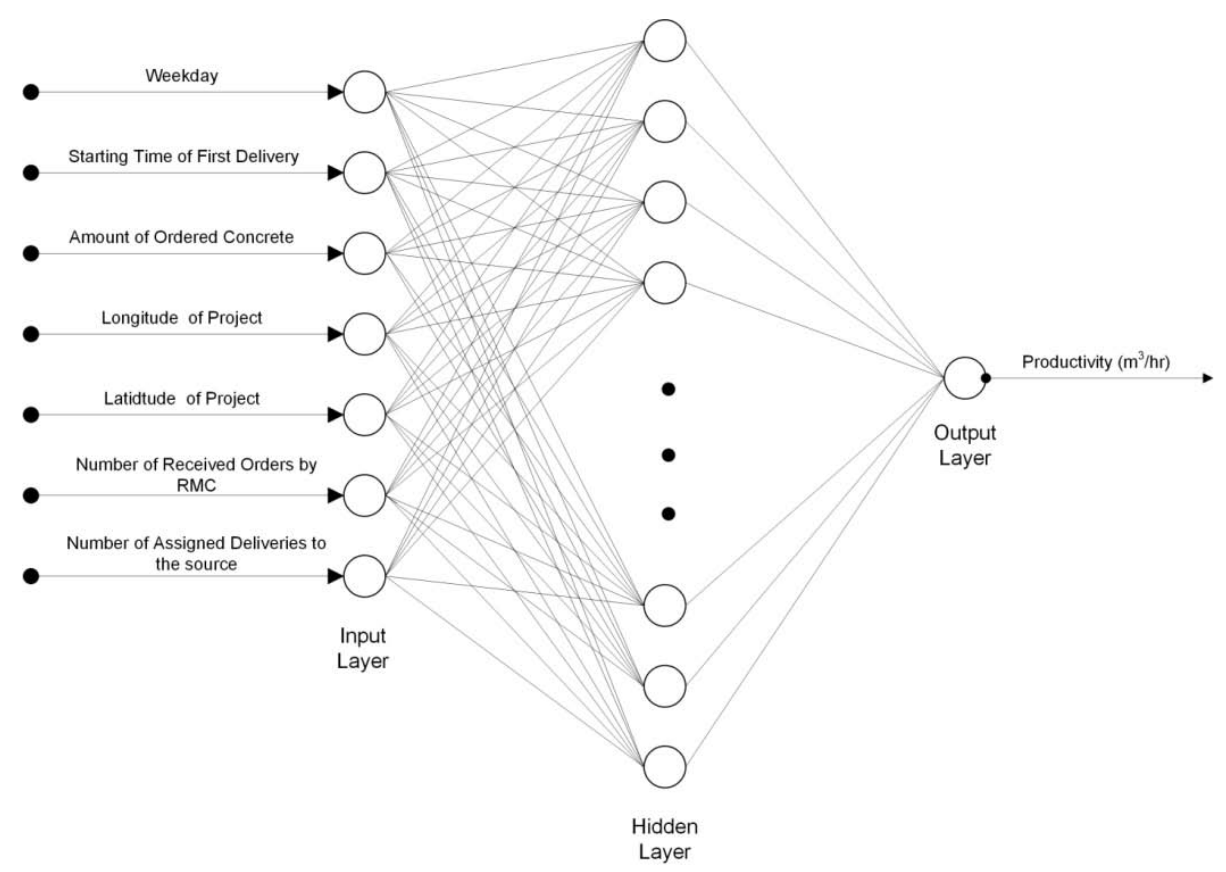

Figure 1. Architecture of ANN model

\section{Data collection}

For testing the proposed ANN model a real database which covers all deliveries of an RMC for a period of 4 months was used. The dataset belongs to the Sydney metropolitan area, which is the biggest city in Australia. It is a useful database for testing the proposed ANN model because it covers many different areas with different traffic patterns. To understand the size of an RMC we can briefly say that on 109 days the RMC was active and supplied 42793 deliveries. The RMC had 17 batch plants and 217 trucks. On about $80 \%$ of days the RMC delivered more than 300 trucks per day. This number on around $50 \%$ of days is more than 500 . 
Most projects need fewer than 5 deliveries and the number of projects that need only one delivery is considerably large. Predicting the productivity is not very important for this size of project; therefore, it focuses only on projects that order more than 5 deliveries on a day. Consequently, 1673 projects were selected for further studies. Studies of RMC problems with this size of database have not been conducted in the literature and it helps the researcher to be more confident about covering the variety of possible situations and scenarios among the collected data. The suggested attributes were obtained from the chosen projects and the training/test set was constructed. In the following section the achieved results are discussed.

\section{Results}

The number of hidden layers as mentioned above is set to 10; $70 \%$ of data (1171 instances) is used for training and $15 \%$ (251 instances) for validation, with the remaining $15 \%$ used for testing the ANN model. MATLAB R2012a automatically scales input values to [0 1] so it does not need to do this job manually. Through the validation the ANN parameters are tuned to find the optimum model by monitoring MSE (Mean Squared Error) (eq. 1) after any changes.

This validation process is very important because it can avoid over fit in the model. This can happen when the ANN model is fitted to the training dataset precisely, thereby losing generalization (Nissen and Nemerson, 2000). For this reason the model is tested with unseen data through validation to make judgment about the trained model. Epoch is one of the critical parameters that are adjusted in validation. An epoch is one training step when all instances of the training dataset are shown in the ANN model. The result of adjusting an epoch is shown in Figure 2, and as it is obvious the best epoch is 5 when the minimum MSE of 10.94 is achieved for validation dataset.

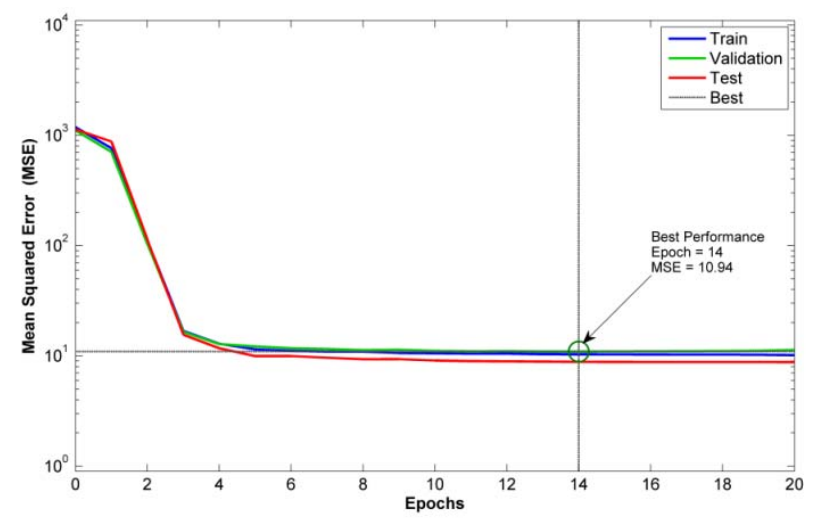

Figure 2. Performance of the ANN model in validation process

The achieved results of training, validation and testing are depicted in Figure 3. The desired behaviour occurs when ANN predictions are exactly equal to actual values. The obtained MSE for training, validation and testing subsequently are 10.34, 10.94 and 8.83. The regression $\mathrm{R}$ values also subsequently are $0.79,0.77$ and 0.81 . The summary of all 1673 instances is shown in Figure 4. From this graph we cannot deduce a trend for errors of the ANN model, therefore the histogram of errors is drawn in Figure 5. This graph shows that, despite the number of disproportionate errors being not too great, the errors larger than 10 belong to the training set. 
Another important issue that we can comprehend from Figure 5 is that around $70 \%$ of training errors and $80 \%$ of validation errors and test errors are in the range of $-2.85,2.18$. This reflects that the ANN model is able to predict good enough values in most of instances. In comparison, the achieved results to the only similar research that was conducted by Graham et al. (2006) show an improvement is obtained. In the best case they achieve 10.76 for MSE while in this paper the 8.83 is achieved for MSE of test dataset and MSE in less than 10 in overall. The only concern here is in relation to the possible correlation between errors and predictions. The residuals for all instances are demonstrated in Figure 6. According to the graph there is no any obvious trend or correlation between errors and targets. Most of productivities are in range of $8-15\left(\mathrm{~m}^{3} / \mathrm{hr}\right)$ which the ANN model predicts those precisely, however for productivities less than $5\left(\mathrm{~m}^{3} / \mathrm{hr}\right)$ and more than $15\left(\mathrm{~m}^{3} / \mathrm{hr}\right)$ the distribution of residuals are expanded gradually. Although that there is no clear trend through this randomly growth, however, this issue can possibly be studied in the future to understand the underlying reasons for this behavior. Generally it is restated that the proposed ANN model is capable to predict productivity of concrete operation with a better accuracy than relevant studies by considering both construction and supply chain parameters.
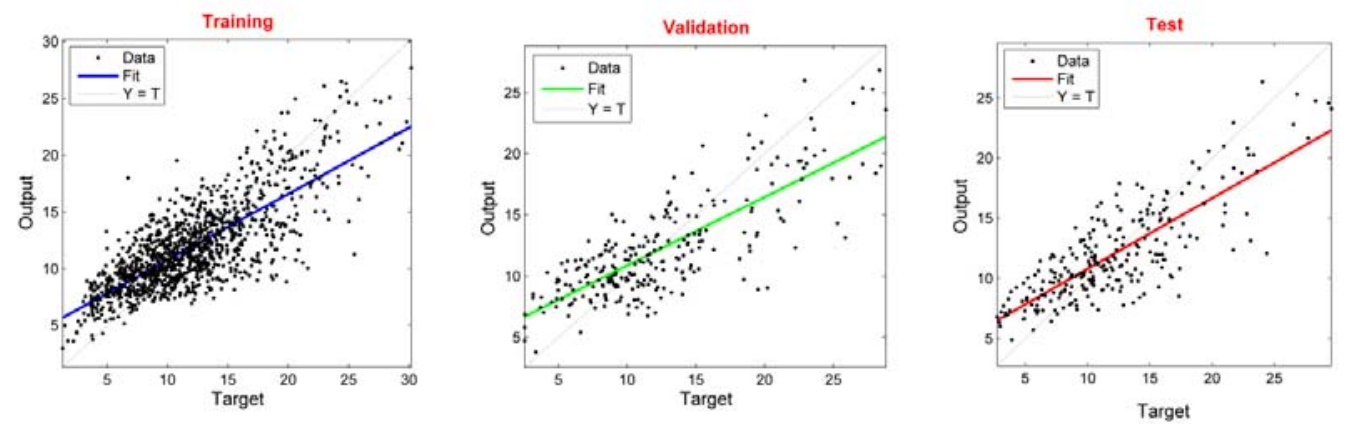

Figure 3. Achieved results of the ANN model in training, validation and test

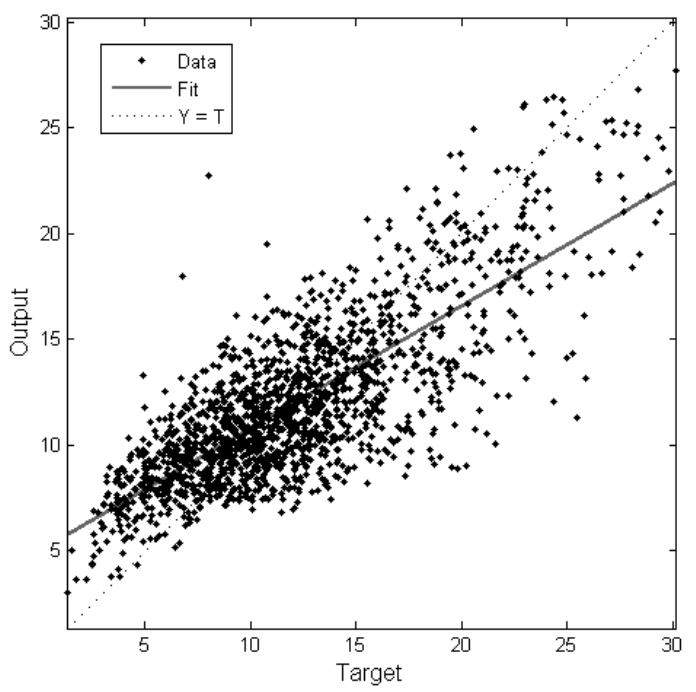

Figure 4. Summary of all instances 


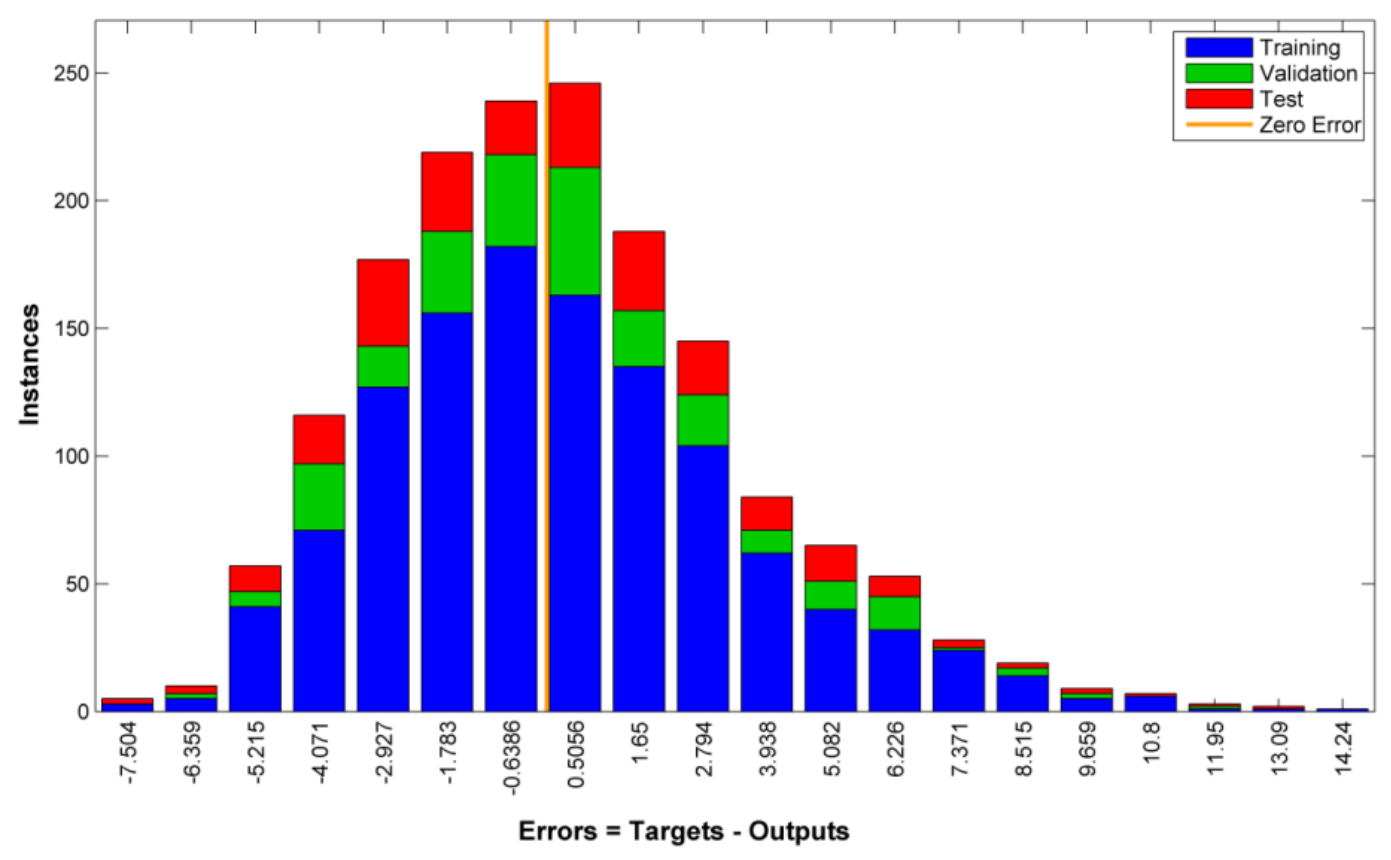

Figure 5. Errors histogram

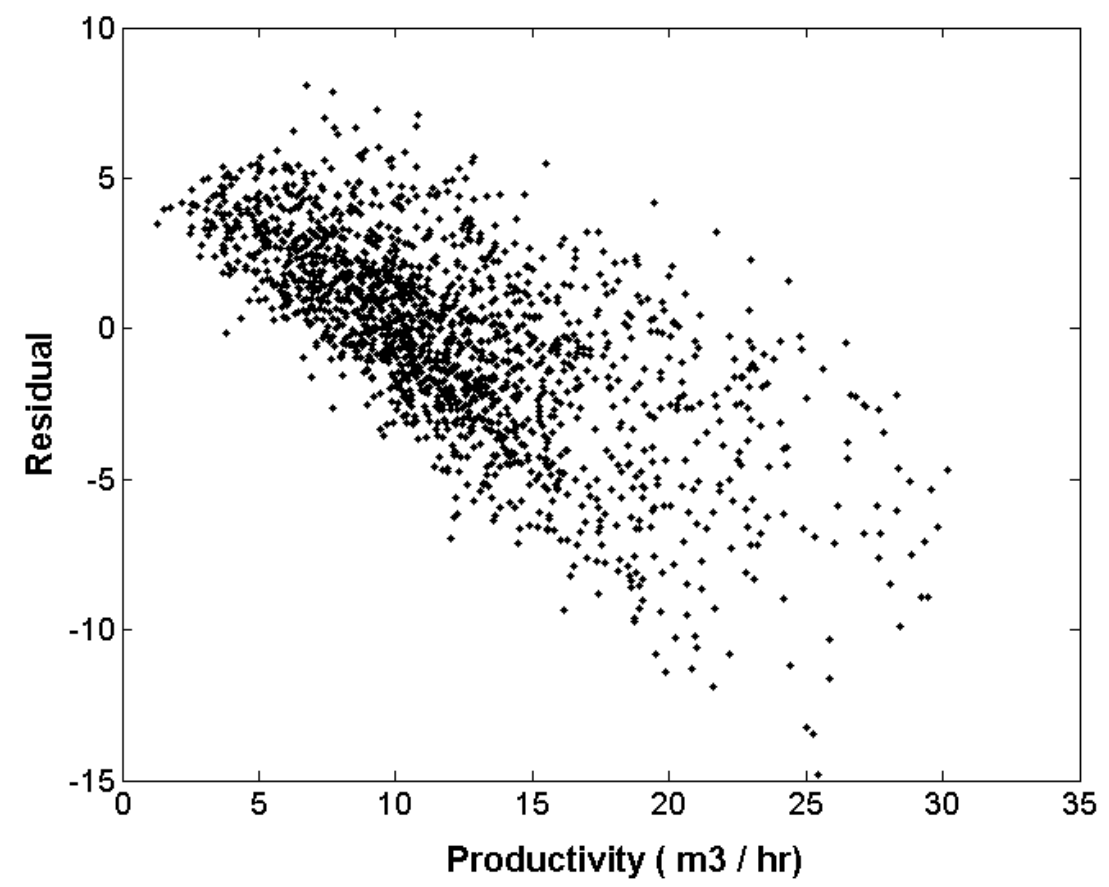

Figure 6. Residual of all instances 
Predicting the productivity of pouring concrete in large projects is a challenging issue because there are a large number of effective variables and also an absence of any theoretical method. Graham et al. (2006) solved this problem via Artificial Neural Network (ANN) by building a database focusing more on construction attributes. In this paper, ANN was hired as well but totally different attributes were applied. In the authors' opinion in mega cities, such as Sydney that has been selected for case study in this paper, the supply chain issues are more critical than the construction parameters. Therefore, by considering these issues a set of attributes can be proposed based on the required data that were collected. The available database consists of 4 months' deliveries of a RMC with 17 depots and more than 200 trucks in the Sydney metropolitan area. The size of the collected database was greater than in similar research in order to cover all real possibilities and scenarios. Although that the size of data which was used in this paper is larger than datasets that have been used in similar approach, however, the achieved results indicate that the proposed ANN model works slightly better than very similar model introduced by Graham et al. (2006) model. This model can be used by both RMCs and clients for predicting the duration of concrete operations and thereby reducing the idleness and cost of equipment in construction sites.

\section{REFERENCES}

[1] Abourizk, S. M. and Wales, R. J. (1997), “Combined discrete-event/continuous simulation for project planning”, Journal of construction engineering and management 123, 11-20.

[2] Armstrong , T. (2013), “The Global Cement Report”, In: 10TH (ed.), International Cement Review.

[3] Asbach, L., Dorndorf, U. and Pesch, E. (2009), "Analysis, modeling and solution of the concrete delivery problem”, European Journal of Operational Research 193, 820-835.

[4] Attalla, M. and Hegazy, T. (2003), "Predicting cost deviation in reconstruction projects: Artificial neural network versus regression”, Journal of Construction Engineering and Management-Asce 129, 405-411.

[5] Borcherding, J. D. and Alarcon, L. F. (1991), "Quantitative effects on construction productivity”, Constr. Law. 11, 1.

[6] Brega, J. R. F., Soria, M. H. A., Marar, J. F. and Sementille, A. C. (1998), An intelligent system for pavement management. In: Rogers, S. K., Fogel, D. B., Bezdek, J. C. and Bosacchi, B. (eds.) Applications and Science of Computational Intelligence. Bellingham: Spie-Int Soc Optical Engineering.

[7] Cao, M., Lu, M. and Zhang, J.-P. (2004), "Concrete plant operations optimization using combined simulation and genetic algorithms", Machine Learning and Cybernetics, Proceedings of 2004 International Conference on, 2004. IEEE, 4204-4209.

[8] Chao, L.-C. and Skibniewski, M. J. (1994), "Estimating construction productivity: Neuralnetwork-based approach”, Journal of Computing in Civil Engineering 8, 234-251. 
[9] Chehayeb, A., Al-Hussein, M. and Flynn, P. (2007), "An integrated methodology for collecting, classifying, and analyzing Canadian construction court cases”, Canadian Journal of Civil Engineering 34, 177-188.

[10] Chen, J. H. and Hsu, S. C. (2007), "Hybrid ANN-CBR model for disputed change orders in construction projects", Automation in Construction 17, 56-64.

[11] Cheng, M. Y., Tsai, H. C. and Liu, C. L. (2009) "Artificial intelligence approaches to achieve strategic control over project cash flows", Automation in Construction 18, 386393.

[12] Cheng, T. M. and Yan, R. Z. (2009), "Integrating messy genetic algorithms and simulation to optimize resource utilization”, Computer-Aided Civil and Infrastructure Engineering 24, 401-415.

[13] Council, W. B. (2009), World Business Council for Sustainable Development/The Cement Sustainability Initiative, Cement Industry Energy and CO2 Performance: Getting the Numbers Right.

[14] Crawford, P. and VOGL, B. (2006), "Measuring productivity in the construction industry", Building Research \& Information 34, 208-219.

[15] Damtoft, J., Lukasik, J., Herfort, D., Sorrentino, D. and Gartner, E. (2008), "Sustainable development and climate change initiatives", Cement and concrete research 38, 115-127.

[16] Darrat, A. F. and Zhong, M. (2000) "On Testing the Random-Walk Hypothesis: A ModelComparison Approach”, Financial Review 35, 105-124.

[17] Dunlop, P. and Smith, S. D. (2004), "Planning, estimation and productivity in the lean concrete pour”, Engineering, Construction and Architectural Management 11, 55-64.

[18] Fast, M. and Palme, T. (2010), "Application of artificial neural networks to the condition monitoring and diagnosis of a combined heat and power plant”, Energy 35, 1114-1120.

[19] Feng, C.-W., Cheng, T.-M. and Wu, H.-T. (2004), “Optimizing the schedule of dispatching RMC trucks through genetic algorithms”, Automation in Construction 13, 327-340.

[20] Feng, C.-W. and Wu, H.-T. (2006), "Integrating fmGA and CYCLONE to optimize the schedule of dispatching RMC trucks”, Automation in Construction 15, 186-199.

[21] Flood, I. and Christophilos, P. (1996), "Modeling construction processes using artificial neural networks", Automation in construction 4, 307-320.

[22] Garcia, J., Lozano, S., Smith, K., Kwok, T. and Villa, G. (2002), “Coordinated scheduling of production and delivery from multiple plants and with time windows using genetic algorithms, Neural Information Processing”, ICONIP'02, Proceedings of the 9th International Conference on, IEEE, 1153-1158.

[23] Graham, L. D., Forbes, D. R. and Smith, S. D. (2006), "Modeling the ready mixed concrete delivery system with neural networks", Automation in construction 15, 656-663.

[24] Humphreys, K. and Mahasenan, M. (2002) Towards a sustainable cement industry, Climate change, sub-study 8, World Business Council for Sustainable Development. 
[25] Imbabi, M. S., Carrigan, C. and Mckenna, S. (2012), “Trends and developments in green cement and concrete technology”, International Journal of Sustainable Built Environment $1,194-216$.

[26] Jin, X. H. and Zhang, G. M. (2011), "Modelling optimal risk allocation in PPP projects using artificial neural networks", International Journal of Project Management 29, 591-603.

[27] Kale, S. and Karaman, E. A. (2011), "Evaluating the Knowledge Management Practices of Construction Firms by Using Importance-Comparative Performance Analysis Maps”, Journal of Construction Engineering and Management-Asce 137, 1142-1152.

[28] Kartam, N. (1996), "Neural Network-Spreadsheet Integration for Earth-Moving Operations”, Computer-Aided Civil and Infrastructure Engineering 11, 283-288.

[29] Kim, D. Y., Han, S. H., Kim, H. and Park, H. (2009), "Structuring the prediction model of project performance for international construction projects: A comparative analysis", Expert Systems with Applications 36, 1961-1971.

[30] Kim, S. (2013), "Hybrid forecasting system based on case-based reasoning and analytic hierarchy process for cost estimation”, Journal of Civil Engineering and Management 19, 86-96.

[31] Ko, C. H. and Cheng, M. Y. (2007), "Dynamic prediction of project success using artificial intelligence”, Journal of Construction Engineering and Management-Asce 133, 316-324.

[32] Kosmatka, S. H., Panarese, W. C., Allen, G. E. and Cumming, S. (2002), Design and control of concrete mixtures, Portland Cement Association Skokie, Ill.

[33] Levenberg, K. (1944) "A method for the solution of certain problems in least squares", Quarterly of applied mathematics 2, 164-168.

[34] Lin, P.-C., Wang, J., Huang, S.-H. and Wang, Y.-T. (2010), "Dispatching ready mixed concrete trucks under demand postponement and weight limit regulation", Automation in Construction 19, 798-807.

[35] Liu, M. and Ling, Y. Y. (2003), "Using fuzzy neural network approach to estimate contractors' markup”, Building and Environment 38, 1303-1308.

[36] Lu, M., Abourizk, S. and Hermann, U. H. (2000), "Estimating labor productivity using probability inference neural network", Journal of Computing in Civil Engineering 14, 241248.

[37] Lu, M., Dai, F. and Chen, W. (2007), "Real-time decision support for planning concrete plant operations enabled by integrating vehicle tracking technology, simulation, and optimization algorithms”, Canadian Journal of Civil Engineering 34, 912-922.

[38] Lu, M. and Lam, H.-C. (2005), "Optimized concrete delivery scheduling using combined simulation and genetic algorithms", Proceedings of the 37th conference on Winter simulation, Winter Simulation Conference, 2572-2580.

[39] Lu, M., Wu, D.-P. and Zhang, J.-P. (2006), A particle swarm optimization-based approach to tackling simulation optimization of stochastic, large-scale and complex systems, Advances in Machine Learning and Cybernetics, Springer. 
[40] Mahasenan, N., Smith, S., Humphreys, K. and Kaya, Y. (2003), "The cement industry and global climate change: current and potential future cement industry $\mathrm{CO} 2$ emissions", Greenhouse Gas Control Technologies-6th International Conference, Oxford: Pergamon, 995-1000.

[41] Marquardt, D. W. (1963), "An algorithm for least-squares estimation of nonlinear parameters", Journal of the Society for Industrial \& Applied Mathematics 11, 431-441.

[42] McCulloch, W. S. and Pitts, W. (1943), "A logical calculus of the ideas immanent in nervous activity", Bulletin of mathematical biology 5, 115-133.

[43] Mehta, P. K. (2009), “Global concrete industry sustainability”, Concrete international 31, 4.

[44] Ming, L. and Hoi-Ching, L. (2009), "Simulation-optimization integrated approach to planning ready mixed concrete production and delivery: Validation and applications", Simulation Conference (WSC), Proceedings of the 2009 Winter, 13-16 Dec. 2009. 25932604.

[45] Moselhi, O., Hegazy, T. and Fazio, P. (1991), "Neural networks as tools in construction", Journal of Construction Engineering and Management-Asce 117, 606-625.

[46] Naso, D., Surico, M., Turchiano, B. and Kaymak, U. (2007), "Genetic algorithms for supply-chain scheduling: A case study in the distribution of ready-mixed concrete", European Journal of Operational Research 177, 2069-2099.

[47] Nissen, S. and Nemerson, E. (2000), Fast artificial neural network library, Available at leenissen. $\mathrm{dk} / \mathrm{fann} / \mathrm{html} /$ files/fann-h. html.

[48] Pan, L., Liya, W., Xihai, D. and Xiang, G. (2010), "Scheduling of dispatching Ready Mixed Concrete trucks trough Discrete Particle Swarm Optimization”, Systems Man and Cybernetics (SMC), IEEE International Conference on, 10-13 Oct. 2010. 4086-4090.

[49] Payr, F. and Schmid, V. (2009), "Optimizing Deliveries of Ready-Mixed Concrete", Logistics and Industrial Informatics, LINDI 2009, 2nd International, IEEE, 1-6.

[50] Portas, J. and Abourizk, S. (1997), "Neural network model for estimating construction productivity", Journal of construction engineering and management 123, 399-410.

[51] Qin, Q., Wang, Q.-G., Li, J. and Ge, S. S. (2013), "Linear and Nonlinear Trading Models with Gradient Boosted Random Forests and Application to Singapore Stock Market", Journal of Intelligent Learning Systems and Applications 5, 1-10.

[52] Rosenthal, E. (2007), “Cement industry is at center of climate change debate”, New York Times, 26.

[53] Savin, D., Alkass, S. and Fazio, P. (1996), “Construction resource leveling using neural networks", Canadian Journal of Civil Engineering 23, 917-925.

[54] Shi, H. W. and Li, W. Q. (2008), Application of PSO-based Neural Network in Quality Assessment of Construction Project, Los Alamitos, Ieee Computer Soc.

[55] Shi, J. J. (1999), “A neural network based system for predicting earthmoving production”, Construction Management \& Economics 17, 463-471. 
[56] Silva, C. A., Faria, J. M., Abrantes, P., Sousa, J. M. C., Surico, M. and Naso, D. (2005), "Concrete Delivery using a combination of GA and ACO. Decision and Control and European Control Conference”, CDC-ECC '05. 44th IEEE Conference on, 12-15 Dec. 2005, 7633-7638.

[57] Sonmez, R. and Rowings, J. E. (1998), "Construction labor productivity modeling with neural networks”, Journal of Construction Engineering and Management 124, 498-504.

[58] Srichandum, S. and Rujirayanyong, T. (2010) "Production scheduling for dispatching ready mixed concrete trucks using bee colony optimization”, Am. J. Engg. \& Applied Sci 3, 823830.

[59] Szu, H., Sheng, Y. and Chen, J. (1992), "Wavelet transform as a bank of the matched filters”, Applied optics 31, 3267-3277.

[60] Thomas, H. R. (1991), “Labor productivity and work sampling: The bottom line”, Journal of Construction Engineering and Management 117, 423-444.

[61] Thomas, H. R. and Daily, J. (1983), "Crew performance measurement via activity sampling”, Journal of Construction Engineering and Management 109, 309-320.

[62] Thomas, H. R., Guevara, J. M. and Gustenhoven, C. T. (1984), "Improving productivity estimates by work sampling”, Journal of construction engineering and management 110, 178-188.

[63] Thomas, H. R. and Sakarcan, A. S. (1994), "Forecasting labor productivity using factor model”, Journal of Construction Engineering and Management 120, 228-239.

[64] Worrell, E., Price, L., Martin, N., Hendriks, C. and Meida, L. O. (2001), “Carbon dioxide emissions from the global cement industry 1", Annual Review of Energy and the Environment 26, 303-329.

[65] Wu, D.-P., Lu, M. and Zhang, J.-P. (2005), "Efficient optimization procedures for stochastic simulation systems. Machine Learning and Cybernetics”, Proceedings of 2005 International Conference on, 2005. IEEE, 2895-2900.

[66] Yan, S., Lai, W. and Chen, M. (2008), "Production scheduling and truck dispatching of ready mixed concrete", Transportation Research Part E: Logistics and Transportation Review 44, 164-179.

[67] Yan, S., Lin, H. and Jiang, X. (2012), "A planning model with a solution algorithm for ready mixed concrete production and truck dispatching under stochastic travel times", Engineering Optimization 44, 427-447.

[68] Zahraee, S. M., Hatami, M., Mohd Yusof, N., Mohd Rohani, J. and Ziaei, F. (2013), "Combined Use of Design of Experiment and Computer Simulation for Resources Level Determination in Concrete Pouring Process”, Jurnal Teknologi 64.

[69] Zor, I., Guzel, A., Ozyurek, H. and Erdogan, E. (2012), “Abnormal Effects of Weekdays on Forecasting Stock Prices by Neural Networks”, European Journal of Social Sciences 29, 244-259. 